\title{
They say coconut oil can aid weight loss, but can it really?
}

Article

Accepted Version

Clegg, M. E. (2017) They say coconut oil can aid weight loss, but can it really? European Journal of Clinical Nutrition, 71 (10). pp. 1139-1143. ISSN 0954-3007 doi:

https://doi.org/10.1038/ejcn.2017.86 Available at https://centaur.reading.ac.uk/80389/

It is advisable to refer to the publisher's version if you intend to cite from the work. See Guidance on citing.

To link to this article DOI: http://dx.doi.org/10.1038/ejcn.2017.86

Publisher: Nature Publishing Group

All outputs in CentAUR are protected by Intellectual Property Rights law, including copyright law. Copyright and IPR is retained by the creators or other copyright holders. Terms and conditions for use of this material are defined in the End User Agreement.

\section{www.reading.ac.uk/centaur}

\section{CentAUR}

Central Archive at the University of Reading

Reading's research outputs online 
1 They say coconut oil can aid weight loss, but can it really?

2

$3 \quad$ Miriam E Clegg

4

5 Functional Food Centre, Department of Sport and Health Sciences, Faculty of Health and

$6 \quad$ Life Sciences, Oxford Brookes University, Gipsy Lane, Oxford OX3 0BP, UK

7

$8 \quad{ }^{*}$ Corresponding author: Miriam Clegg, Functional Food Centre, Department of Sport and

9 Health Sciences, Faculty of Health and Life Sciences, Oxford Brookes University, Gipsy

10 Lane, Oxford OX3 OBP, UK

11 Email: mclegg@brookes.ac.uk; Ph: +44 1865484365

12

13

14 Running title: Coconut oil for weight loss

15

Keywords: Coconut oil, MCT oil, satiety, energy expenditure, body weight

17

18

Conflict of interest.

19

The author declares no conflict of interest.

20

21

22

23

24

25

26 
30 There has in recent years, been much media speculation and consumer interest in the 31 beneficial satiating properties of consuming coconut oil and it's potential to aid weight loss.

32 However the media has primarily cited studies using MCT oil. The current perspective looks 33 at the research that is available on coconut oil. It examines if and how MCT related research can be applied to coconut oil and if there is potential for coconut oil to aid weight loss. The current report indicates a lack of consistent evidence on the topic of coconut oil, satiety and weight loss. Given both the publicity and the increased consumption of coconut oil further research, particularly long term clinical trials, in this area are warranted.

38 
57 Coconut oil has gained considerable popularity in recent years with coconut oil in food and beverages accounting for $26 \%$ of food and drink new product launches in 2012 , this is an increase from $15 \%$ in 2008 (1). Coconut oil exports across Asia have also grown 3.3\% annually over the past five years, according to the Asian Pacific Coconut Community (2). This is not surprising given the numerous ways that coconut oil has been identified by the media, to potentially improve our lives. Articles are wide ranging promoting adding it to stirfries, baking with it and even adding it to coffee $(3,4)$. Many media articles promote the consumption of coconut oil for weight loss, advocating similar health benefits to that of medium chain triglycerides (MCT). This has contributed to an increase in intake of coconut oil in recent years (5). Coconut oil is said to aid weight loss through a combination of increased energy expenditure and satiety induced by MCT. MCT are dietary triglycerides with fatty acids chains that are 6 to 12 carbon atoms in length (6). MCT have a smaller molecular weight than long chain triglycerides. This allows them to be more rapidly and completely hydrolysed, and absorbed when there are decreased intraluminal concentrations of pancreatic enzymes and bile salts (7). During digestion, MCT are converted to mediumchain fatty acids (MCFA) and transported directly in the portal venous system to the liver, as opposed to being transported as chylomicrons in the lymphatic system like LCT (8). MCT therefore bypass peripheral tissues, including adipose tissue, which makes them less likely to be deposited into the adipose tissue via the actions of hormone-sensitive lipase (6). Finally, MCFA can cross the mitochondrial membrane of the liver and muscle independently of the acylcarnitine transfer system, this makes them a more readily available energy source that is likely to be utilised more rapidly (9).

It has been proposed that MCT can affect satiety via a number of mechanisms; however a lot is still unknown. Potential mechanisms include the production of ketones due to the increased acetyl-CoA influx which is necessary to oxidize fatty acids (10). Furthermore, Van Wymelbeke et al (11) and Rolls et al (12) indicate that the increase in satiety maybe due to the rapid rate of absorption of MCT. Where LCT result in two peaks during absorption; the 
initial peak at the point of ingestion and a second delayed peak at the beginning of the next meal, MCT are fully absorbed at the point of ingestion (13). Hence, MCT may contribute to satiation due to complete absorption mechanism.

The evidence for both increases in diet induced thermogenesis (14-24) and reduced food intake $(11,12,25-29)$ following the consumption of MCT has been well documented, with interventions using MCT oil indicating that there is potential for it to help aid weight loss (10, 30-33) (Table 1). However it needs to be emphasised that MCT oil and coconut oil are not the same thing. Lauric acid (carbon chain length 12) is found in much larger quantities in coconut oil, making up $47.7 \%$ of the total fat, where no lauric acid is found in MCT oil. Other MCFA in coconut oil are capric acid (C10-5.5\%), caprylic acid (C8-7.6\%) and caproic acid $(\mathrm{C} 6-0.52 \%)(34)$. There is some debate as to whether lauric acid is a MCT or not and this is demonstrated in how it is utilized in the body. Unlike with pure MCT oil containing fatty acids of shorter carbon length (C6-C10), only twenty to thirty percent of lauric acid is taken directly to the liver to be used as energy via the portal vein (35). This means that in total only $23.16 \%$ of the coconut oil contains MCTs that is absorbed and metabolised in the same way as pure MCT oil.

Studies on satiety and MCT have shown that $3 g$ is not sufficient to have an effect on satiety $(26,27)$. However this is in contrast to a study by Rolls et al (12) that showed a dose as low as $2.9 \mathrm{~g}$ (100kcal containing $24 \% \mathrm{MCT})$ reduced food intake in dieters but had no effect in non-dieters. This obviously has practical implications as it is dieters that are most likely to want to see the satiating effects. The other studies that have shown an effect have used much higher doses of $\sim 25 \mathrm{~g}(11,25,29)$. Studies looking at energy expenditure have shown doses of $5 \mathrm{~g}$ have the ability to increase postprandial thermogenesis (18). However, similar to satiety the majority of other studies tended to use much larger doses of greater than $20 \mathrm{~g}(17$, $21,36)$. For weight loss, similarly doses of $5 \mathrm{~g}$ of MCT for 12 week resulted in significant decreases in body fat, subcutaneous and visceral fat (31). 
114 This shows that doses as low as $5 \mathrm{~g}$ and perhaps $3 \mathrm{~g}$ may have an effect on satiety and body weight; however the majority of the research has used MCT amounts much higher than this. Nonetheless, if a dose as low of $5 \mathrm{~g}$ MCT per day is sufficient to have beneficial effects on weight management then $21.6 \mathrm{~g}$ of coconut oil would be required to obtain sufficient amounts of MCFA. Current UK guidelines limit the intake of saturated to a maximum of just $21 \mathrm{~g}$ in females and $31 \mathrm{~g}$ in males (19-64 years) (37). Hence at the lowest dose of coconut oil known to have an effect on body weight, people will have reached or almost reached their total saturated fat intake for the day.

Two studies examining the effects of coconut oil compared to LCTs reported no increase in satiety and no effect on food intake $(38,39)$ (Table 2). Poppit et al $(39)$ found no difference in visual analogue scale ratings of satiety or differences in ad libitum food intake at lunch following the consumption of either coconut oil (containing $10 \mathrm{~g} \mathrm{MCT}$ ), high short chain triglyceride (3g SCT, $7 \mathrm{~g} \mathrm{MCT)} \mathrm{(from} \mathrm{soft} \mathrm{fraction} \mathrm{milk} \mathrm{fat)} \mathrm{or} \mathrm{long} \mathrm{chain} \mathrm{triglycerides} \mathrm{(from}$ tallow). Rizzo et al (38) found that in a dinner meal following ice-cream with varying quantities of coconut oil there was trend towards reduced consumption with the coconut oil, however this was compensated for later when there was a significant increase in snack consumption resulting in no overall difference between the ice-creams. The amounts of coconut oil used here are $7.5 \mathrm{~g}$ coconut oil (high dose) consisting of only $\sim 4.8 \mathrm{~g} \mathrm{MCT}$ (carbons 6-12). This study should be commended on giving the coconut in a realistic form study published across three papers providing 14 days of coconut oil, found no effect on total energy expenditure or thermic effect of feeding. However they did find an increase in basal metabolic rate after 7 days but not 14 days and an increase in endogenous long chain 
saturated fatty acid oxidation after 14 days $(19,20,24)$. In this study, caprylic and capric acid made up $7.9 \%$ of the energy intake of the diet and lauric acid made up $17.7 \%$.

143 Currently there appears to be a lack of research in this area and to the best of the author's knowledge there are no studies looking at the effect of coconut oil on weight loss and none comparing it to MCT oil. Further work is needed in this area to confirm these preliminary calculations however indications would suggest that the use of coconut oil as a practical means of increasing satiety are not credible. The research available on the use of coconut oil on satiety and energy expenditure is limited and particularly there have been no long term clinical trials looking at the effects on weight loss. Given both the publicity and the increased consumption of coconut oil further research in this area is warranted.

\section{References}

153 1. Mintel. Tropical storm in the food and drink market: launches of coconut water 154 quintuple over the past five years 2013 [Available from: http://www.mintel.com/presscentre/food-and-drink/launches-of-coconut-water-quintuple-over-the-past-five-years.

2. Mahr K. Why the Coconut Craze Isn't Helping Farmers 2012 [Available from: http://business.time.com/2012/12/05/why-the-coconut-craze-isnt-helping-farmers/. 3. Waters J. Bulletproof coffee: is adding butter to your brew a step too far? 2014

159 [Available from:

160 https://www.theguardian.com/lifeandstyle/wordofmouth/2014/nov/25/bulletproof-coffee-is-

161 adding-butter-to-your-morning-coffee-a-step-too-far.

162 4. Sacks K. 6 Ways to Cook With Coconut Oil: Epicurious; 2015 [Available from:

163 http://www.epicurious.com/ingredients/how-to-cook-with-coconut-oil-article.

164 5. Lockyer S, Stanner S. Coconut oil - a nutty idea? Nutrition Bulletin. 2016;41:42-54.

165 6. Bach AC, Babayan VK. Medium-chain triglycerides: an update. The American journal 166 of clinical nutrition. 1982;36(5):950-62. 
167 7. Fernandes J, van de KJ, Weijers HA. Differences in absorption of the various fatty

168 acids studied in children with steatorrhea. The Journal of clinical investigation. 1962;41:488-

16994.

170 8. Bloom B, Chaikoff IL, Reinhardt. Intestinal lymph as pathway for transport of 171 absorbed fatty acids of different chain lengths. Am J Physiol. 1951;166(2):451-5.

172 9. Williamson JR, Browning ET, Scholz R, Kreisberg RA, Fritz IB. Inhibition of fatty acid 173 stimulation of gluconeogenesis by $(+)$-decanoylcarnitine in perfused rat liver. Diabetes. 1968;17(4):194-208.

10. Tsuji H, Kasai M, Takeuchi H, Nakamura M, Okazaki M, Kondo K. Dietary mediumchain triacylglycerols suppress accumulation of body fat in a double-blind, controlled trial in healthy men and women. J Nutr. 2001;131(11):2853-9.

11. Van Wymelbeke V, Louis-Sylvestre J, Fantino M. Substrate oxidation and control of food intake in men after a fat-substitute meal compared with meals supplemented with an isoenergetic load of carbohydrate, long-chain triacylglycerols, or medium-chain triacylglycerols. The American journal of clinical nutrition. 2001;74(5):620-30. 12. Rolls BJ, Gnizak N, Summerfelt A, Laster LJ. Food intake in dieters and nondieters after a liquid meal containing medium-chain triglycerides. The American journal of clinical nutrition. 1988;48(1):66-71.

13. Fielding BA, Callow J, Owen RM, Samra JS, Matthews DR, Frayn KN. Postprandial lipemia: the origin of an early peak studied by specific dietary fatty acid intake during sequential meals. The American journal of clinical nutrition. 1996;63(1):36-41.

14. Alexandrou E, Herzberg GR, White MD. High-level medium-chain triglyceride feeding and energy expenditure in normal-weight women. Can J Physiol Pharmacol. 2007;85(5):50713.

15. Binnert C, Pachiaudi C, Beylot M, Hans D, Vandermander J, Chantre P, et al. Influence of human obesity on the metabolic fate of dietary long- and medium-chain triacylglycerols. The American journal of clinical nutrition. 1998;67(4):595-601. 
16. Dulloo AG, Fathi M, Mensi N, Girardier L. Twenty-four-hour energy expenditure and urinary catecholamines of humans consuming low-to-moderate amounts of medium-chain triglycerides: a dose-response study in a human respiratory chamber. European journal of clinical nutrition. 1996;50(3):152-8. 17. Flatt JP, Ravussin E, Acheson KJ, Jequier E. Effects of dietary fat on postprandial substrate oxidation and on carbohydrate and fat balances. The Journal of clinical investigation. 1985;76(3):1019-24.

18. Kasai M, Nosaka N, Maki H, Suzuki Y, Takeuchi H, Aoyama T, et al. Comparison of diet-induced thermogenesis of foods containing medium- versus long-chain triacylglycerols. J Nutr Sci Vitaminol (Tokyo). 2002;48(6):536-40. 19. Papamandjaris AA, White MD, Raeini-Sarjaz M, Jones PJ. Endogenous fat oxidation during medium chain versus long chain triglyceride feeding in healthy women. Int $\mathrm{J}$ Obes Relat Metab Disord. 2000;24(9):1158-66.

20. Papamandjaris AA, White MD, Jones PJ. Components of total energy expenditure in healthy young women are not affected after 14 days of feeding with medium-versus longchain triglycerides. Obesity research. 1999;7(3):273-80. and long-chain triglycerides in man. The American journal of clinical nutrition. $1986 ; 44(5): 630-4$.

22. St-Onge MP, Ross R, Parsons WD, Jones PJ. Medium-chain triglycerides increase energy expenditure and decrease adiposity in overweight men. Obesity research. 2003;11(3):395-402.

23. St-Onge MP, Bourque C, Jones PJ, Ross R, Parsons WE. Medium- versus longchain triglycerides for 27 days increases fat oxidation and energy expenditure without resulting in changes in body composition in overweight women. Int $\mathrm{J}$ Obes Relat Metab Disord. 2003;27(1):95-102. 
24. White MD, Papamandjaris AA, Jones PJ. Enhanced postprandial energy expenditure with medium-chain fatty acid feeding is attenuated after $14 \mathrm{~d}$ in premenopausal women. The American journal of clinical nutrition. 1999;69(5):883-9.

25. Coleman H, Quinn P, Clegg ME. Medium-chain triglycerides and conjugated linoleic acids in beverage form increase satiety and reduce food intake in humans. Nutrition research (New York, NY. 2016;36(6):526-33.

26. Kovacs EM, Westerterp-Plantenga MS, de Vries M, Brouns F, Saris WH. Effects of 2week ingestion of (-)-hydroxycitrate and (-)-hydroxycitrate combined with medium-chain triglycerides on satiety and food intake. Physiol Behav. 2001;74(4-5):543-9.

27. Kovacs EM, Westerterp-Plantenga MS, Saris WH. The effects of 2-week ingestion of (--)-hydroxycitrate and (--)-hydroxycitrate combined with medium-chain triglycerides on satiety, fat oxidation, energy expenditure and body weight. Int J Obes Relat Metab Disord. $2001 ; 25(7): 1087-94$.

28. Stubbs RJ, Harbron CG. Covert manipulation of the ratio of medium- to long-chain triglycerides in isoenergetically dense diets: effect on food intake in ad libitum feeding men. Int J Obes Relat Metab Disord. 1996;20(5):435-44.

29. Van Wymelbeke V, Himaya A, Louis-Sylvestre J, Fantino M. Influence of mediumchain and long-chain triacylglycerols on the control of food intake in men. The American journal of clinical nutrition. 1998;68(2):226-34.

30. Han JR, Deng B, Sun J, Chen CG, Corkey BE, Kirkland JL, et al. Effects of dietary medium-chain triglyceride on weight loss and insulin sensitivity in a group of moderately overweight free-living type 2 diabetic Chinese subjects. Metabolism: clinical and experimental. 2007;56(7):985-91. margarine containing medium-chain triacylglycerols on body fat reduction in humans. $\mathrm{J}$ Atheroscler Thromb. 2003;10(5):290-8. 
246 32. St-Onge MP, Bosarge A. Weight-loss diet that includes consumption of medium-

247 chain triacylglycerol oil leads to a greater rate of weight and fat mass loss than does olive oil.

248 The American journal of clinical nutrition. 2008;87(3):621-6.

249 33. St-Onge MP, Jones PJ. Greater rise in fat oxidation with medium-chain triglyceride

250 consumption relative to long-chain triglyceride is associated with lower initial body weight

251 and greater loss of subcutaneous adipose tissue. Int J Obes Relat Metab Disord.

$252 \quad 2003 ; 27(12): 1565-71$.

253 34. Orsavova J, Misurcova L, Ambrozova JV, Vicha R, Mlcek J. Fatty Acids Composition

254 of Vegetable Oils and Its Contribution to Dietary Energy Intake and Dependence of

255 Cardiovascular Mortality on Dietary Intake of Fatty Acids. Int J Mol Sci. 2015;16(6):12871-

25690.

257 35. Denke MA, Grundy SM. Comparison of effects of lauric acid and palmitic acid on

258 plasma lipids and lipoproteins. The American journal of clinical nutrition. 1992;56(5):895-8.

259 36. Clegg ME, Golsorkhi M, Henry CJ. Combined medium-chain triglyceride and chilli

260 feeding increases diet-induced thermogenesis in normal-weight humans. European journal

261 of nutrition. 2013;52(6):1579-85.

262 37. Public Health England. Governement Dietary Recommendations London2016

263 [Available from:

264 https://www.gov.uk/government/uploads/system/uploads/attachment data/file/547050/gover

265 nment dietary recommendations.pdf.

266 38. Rizzo G, Masic U, Harrold JA, Norton JE, Halford JC. Coconut and sunflower oil

267 ratios in ice cream influence subsequent food selection and intake. Physiol Behav.

$268 \quad 2016 ; 164(P t A): 40-6$.

269 39. Poppitt SD, Strik CM, MacGibbon AK, McArdle BH, Budgett SC, McGill AT. Fatty

270 acid chain length, postprandial satiety and food intake in lean men. Physiol Behav.

$2712010 ; 101(1): 161-7$.

272 